\title{
Qualitative Acceptance Model of Augmented Reality from the Perspective of Personalists
}

\author{
Sabrina Romina Sorko*, Joachim Komar
}

\begin{abstract}
Smart devices and the corresponding new technologies have established themselves within our society. Since the release of the smartphone game Pokémon Go, the field of augmented reality (AR) - the enrichment of reality with information, realized by smart devices such as tablets, data glasses or smartphones - has been experiencing an upswing. Additionally, the industry is starting to integrate AR applications to increase efficiency. In this respect, HR managers play a key role in the implementation of such technology. They maintain direct contact with employees, have an overview of the entire company and thus are often responsible for change processes. The paper analyses the potential of AR within a company from a personalist's point of view and discusses critical factors both in theory and practice. The paper validates the technological possibilities and shows results from a qualitative analysis from focus group discussions. The qualitative acceptance model displays factors influencing the implementation of AR.
\end{abstract}

Keywords: acceptance model; Augmented Reality (AR); human resources; process optimization; Technology Acceptance Model (TAM)

\section{INTRODUCTION}

We live in the age of digital transformation - not only companies are changing, but also the private sector is changing due to new technical possibilities $[1,2]$. Smart devices already play a major role within the society and thus they enable the spread of further technological applications. One technology that uses such hardware is augmented reality (AR) - the enrichment of reality with information, realized by smart devices. Although the technology was used in the first approaches already in the 1960s, the spread of AR applications occurred only in the recent years [3]. Looking at trend analyses, the industry is increasingly implementing AR applications to increase efficiency $[4,5]$. The opportunities that AR brings with it offer optimization potential along the entire value chain. By enriching reality with targeted realtime information and the possibility of flexible access to data and systems, new ways of working arise: spatial, temporal and content related [6].

In this respect, HR managers play a key role in the implementation of such technology. They maintain direct contact with employees, have an overview of the entire company and thus are often responsible for change processes [7]. Therefore, when disseminating AR in companies, it is important to consider the perspective and experience of HR managers.

In this context, the question arises as to the importance of AR from the HR perspective, and which factors influence the implementation of the technology. Of particular interest is the question of technology acceptance.

Thus, the paper analyses the potential of AR within a company from a personalist's point of view and discusses critical factors both in theory and practice. The paper validates technological possibilities and shows results of a qualitative analysis from focus group discussions. The thereof developed qualitative acceptance model displays factors influencing the implementation of AR. Based on this, the paper contains recommendations for companies to increase the acceptance of the AR technology.

\section{AUGMENTED REALITY}

Although a wider audience first got acquainted with AR in the early 2010s, the concept of the technology has existed for much longer [3]. The first rudimentary prototype of a head-mounted AR-device already existed in 1968 [8]. It took further 24 years until the term augmented reality first appeared in literature [9]. In this period, the reality-virtuality continuum was also created, which is a model for defining $\mathrm{AR}$ and related technologies that is still relevant to this day [10].

Despite the efforts of the scientific community to bring together the different directions of literature into a unified model [11], the meaning of the terms is still fragmented. This is, among other things, because companies operating in this business field introduce new terms for marketing purposes or redefine the existing ones [12].

Contradicting Milgram/Kishimo [10], we do not differentiate between mixed reality and augmented reality in this paper due to the divergence of delimitations and definitions even among the experts of the field [12]. Since technological aspects are not the core concern of this paper, we simplify the terminology by using augmented reality in a wider sense as an umbrella term for every system that is able to superimpose interactive digital information or objects onto the view of the real environment in real-time.

Speaking from a technical perspective, an AR system consists of a combination of hardware and software [13]. The following components are seen as the minimum requirements for a functioning AR implementation [14]:

- Video capture of the real worldview as the basis for the following augmentation of a scene.

- Tracking of the AR device's position and motion to generate a moving coordinate system of the user's point of view.

- Geometric registration of the surrounding space to correctly position and orient the digital content.

- Rendering of the digital content based on the previous device tracking and geometric registration of the surrounding space. 
- $\quad$ Output of a video stream to visualize the result through a display.

The benefits of the technology boil down to three key capabilities [15]:

- Visualization: ability to comprehensibly reveal insights of complex data sets in a context-sensitive manner.

- Instruction: ability to deliver training and coaching in an effective and efficient way by providing on-site, step-bystep, real-time visual guidance.

- Interaction: ability to add new dimensions of interactivity through the use of voice control, gesture recognition, eye-tracking, etc.

A multitude of devices is available for a practical implementation of AR [3]. Depending on the requirements of the planned use scenario, a common smartphone could be sufficient, whereas other situations might require a highly specialized and individualized device such as data-glasses that are integrated into personal protective equipment. The same is true for the corresponding software. While common use-cases are often solvable with the available standardsoftware, highly individualized use-cases might also require some degree of individual software development.

\subsection{Potentials and Challenges for the Industry}

AR is not seen as "the new thing" anymore: AR entered the "trough of disillusionment" in the 2018 Version of the Gartner's Hype Cycle and is not included in the 2019 revision anymore, which indicates that the technology has established itself on the market $[4,5]$. This statement is also supported by empirical data. A survey from 2018 found an adoption rate of $13 \%$ with $42 \%$ of the companies stating that they plan to adopt augmented reality in their company by 2021 [16].

The manufacturing industry, especially the automotive sector, is one of the frontrunners of the technology [17] and it uses AR along the whole value chain. From product development to human resources - no area remains unaffected.

A study from 2019 focuses on the status quo of the technology in practice. Out of nearly 150 companies of different sizes in Germany, $46.3 \%$ said that they already use augmented reality in their companies. The main areas of application are step-by-step instructions (45\%), remote assistance (39\%) in particular and knowledge transfer $(38 \%)$ in general, whereby very specific use cases such as pick-byvision $(22 \%)$ or product simulation $(32 \%)$ were also mentioned [18].

Companies that have managed to successfully integrate AR into their business processes report substantial improvements in terms of productivity and costs [15].

The aforementioned key capabilities will transform into key success factors with further progression of digital transformation. Customers increasingly demand highly customized products, which in turn requires high flexibility of suppliers to be able to fulfil this need [19]. AR can help achieve this goal while ensuring that the company remains competitive through high efficiency.
The arising technical challenges are dependent on the area of application and cannot be generalized. On the one hand, AR implementation in the field of product development will likely require three-dimensional interaction capabilities and a connection to other systems that are used in this context (e.g. CAD-systems). On the other hand, an AR system used for remote assistance might only require simple, widely available hardware such as tablets or smartphones with a Wi-Fi connection, a microphone and a camera, as well as a corresponding (standalone) software that provides the functionality.

Each use case, as well as the environment in which the use case is located, requires an individual set of technical requirements for the AR solution. Therefore, when implementing $\mathrm{AR}$, it is important to define the desired use cases and analyse the application environment in order to make an adequate hardware and software selection.

As with any other major technology changes, there are not only challenges in terms of technology, but also in the areas of culture and organization. AR is no exception [20]. Therefore, a holistic implementation process is indispensable.

\subsection{Implementation Process}

The use of AR within the industry necessarily entails a change in work processes. Work is reorganized and thus depending on the area of the AR application - hierarchical structures and decision-making competencies are changed. [21] The latter occurs, for example, when workers in production access ERP systems bidirectionally via AR systems. However, not only the activity in the narrower sense is subject to change, but what also changes are the ways of communication and interaction, as well as the socio-technical system. [22, 23] There is a shift in the core competencies of activities to be performed and controlled. In this context, Bauernhansl 2014 [24] speaks of "augmented operators" along the value chain.

The formulation of an introduction strategy is especially necessary for the implementation of IT-supported solutions, since it defines the goal and framework of the implementation [25]. Additionally, systematic support, particularly in the case of comprehensive changes, is also conducive to successful implementation. In this respect, there are different approaches from theory and practice.

Research shows that the resistance of employees and a lack of change-competence are main reasons for the failure of a change process [26, 27]. Often the awareness for the necessity is missing and thus no acceptance for the new solution - in this case the use of AR - can be achieved. Krüger 2006 therefore recommends involving employees at different hierarchical levels and from different areas of the company right at the start of the change process [28]. The focus is on the keywords job satisfaction and employee retention [29].

It is also important to know the factors that affect the acceptance of the workforce. For the introduction of AR, the following main factors can be derived:

Usability plays a decisive role, especially when new technologies are used. Accordingly, the technical solution 
should be intuitive, self-explanatory and easy to use [30]. In connection to this, there are requirements concerning the organizational framework. Thus, the availability of learning opportunities plays an essential role. These should also be prepared in an understandable way and, in particular, be targeted. Furthermore, the transparency of the project and the underlying motivation for the implementation is a critical factor. If this is not given, there is a risk that employees will perceive the use of AR as a monitoring measure and actively work against it as a reaction [31]. Employability [32] and the extended decision-making competencies made possible by AR also place demands on management. The nature of participation options and the support $[32,33]$ provided by managers are further critical factors. Here, too, the more successfully these factors are taken into account, the less uncertainty employees feel [21]. All these factors are based on a culture of trust in which employees and management interact at an eye level.

At this point, it should also be mentioned that the use of AR also has medium to long-term effects on the expectations of employees in other areas of the company. For example, the expectation of on-demand training or flexible work opportunities increases [34].

All these areas of influence and fundamental considerations regarding employee satisfaction should be incorporated into the company's human resources strategy [21]. HR therefore becomes a key element of implementation projects in general and thus also with regard to the introduction of AR.

\section{HUMAN RESOURCES}

The tasks of human resource management are manifold and range from personnel planning, recruitment and onboarding to personnel development and controlling. Additionally, human resources (HR) is the point of contact for employees and managers for all personnel matters [7]. It is therefore obvious that HR managers not only know their colleagues well, but also play a decisive role as a link in change processes [35].

Looking at the approach of Krüger 2006, analysing the initial situation is the starting point of every change process [28]. People who, on the one hand, can grasp the company as an overall system and, on the other, are familiar with the social structures, communication structures and corporate culture are in high demand. This knowledge is necessary in many ways:

- HR helps detect the right change agents throughout the company.

- Formal and informal channels of communication can be supplied regularly and systematically.

- HR usually has a holistic view of the company and can therefore offer unbiased solutions.

- HR can assess the need for further training and provide suitable further training measures.

- The focus is always on the corporate climate and, in connection with this, on employee satisfaction.
In this respect, HR has a huge influence on change processes and should be taken into account when thinking of implementations.

Derived from this initial situation, the views and experiences of personnel managers were collected for the presented AR acceptance model.

\section{METHODOLOGY}

The qualitative acceptance model developed in this paper is based on the Technology Acceptance Model (TAM) according to Davis 1989 and the further development of TAM 2 according to Venkatesh/Davis in the year 2000 [36]. TAM (2) tries to explain the individual usage behaviour of technologies - especially information systems - by means of different influencing parameters such as experience, relevance or usability.

The core of the model defines the subjectively perceived practicability and usability of a technical solution, which has a direct effect on the readiness for use, which in turn leads to corresponding user behaviour [36]. The basic premise is that employees always strive for solutions that require little implementation effort, but have a high direct positive effect on their own work performance. If this ratio is perceived as sufficient, this increases the intention to use the new technology. This basic behaviour pattern is influenced by various factors, which are again influenced by the subjective perception of employees. According to Venkatesh/Davis 2000 , the perceived usefulness is in particular subject to decisive spheres of influence, which are both work-related and socially shaped. Regarding their job, the positive impact of the new technology on their own tasks (job relevance) [36], as well as the quality of the performance achieved by using the technology (output quality) [37], are taken into account. In this respect, it is important that the achieved improvements are also directly related to the use of the technology (result demonstrability) $[38,36]$.

In assessing the impact of the new technology on the work situation, potential effects on the social work environment are also included. In particular, the effect of the technology on internal reference groups subjectively perceived as important or the protection of one's own internal status should be mentioned in this respect (image) $[38,36]$. Thinking about image is accompanied by the human need to adjust one's own actions to the expectations of the environment. Thus, the opinion of people who are subjectively considered important has a greater influence in this respect (subjective norm) [39]. According to Venkatesh/Davis 2000, these subjective norms not only influence the characterization of the image and the perceived usefulness of the new technology, but there is also a direct correlation with the intention to use [36].

In addition to these direct influencing factors, two further spheres of influence were identified in the TAM 2 model, which indirectly influence the acceptance over time via the subjective standards. On the one hand, the experience gained with the technology contributes to acceptance - positive ones will increase, negative ones will decrease (experience) [36]. On the other hand, the personally perceived negative pressure 
to perform with regard to the use of the technology. The higher the voluntariness, the greater the willingness to use the new technology and to accept it in the future (voluntariness) $[40,38]$.

Since its development, the model has been validated and confirmed by various authors and is therefore often used as an empirical method.

To develop the qualitative acceptance model presented within this contribution, a three-phase methodological approach was applied. In phase one, the relevant literature was analysed and the content framework of the acceptance model was developed. For this purpose, the crucial factors mentioned in TAM 2 were used and applied to the industrial use of AR.

Phase two comprised qualitative focus groups, which were used to examine the previously developed factors influencing the acceptance of AR from different perspectives relevant to practice. This phase represents the practical validation of the previously derived model. The target group consisted of human resources representatives from the manufacturing industry and industry-related service providers who already had a basic interest in AR.

The latter was ensured by the fact that participation in the focus group was on a voluntary basis. In total, a sample of $n$ $=63$ could be reached. In accordance with the main tasks of human resources, the focus group examined the topic "Challenges/success criteria for the introduction of AR in the industry" from three perspectives: the employees, the management (including strategic considerations) and the organization in general. The 63 participants worked out a total of 49 nominations, which could be summarized into 8 clusters of content:

- Training/Learning

- Willingness to use AR

- Employee participation

- Communication

- Data Protection

- Benefit-orientation

- Strategic Value

- Ergonomics.

In phase three, the theoretical and practical findings were combined and a practice-relevant qualitative acceptance model for the use of Augmented Reality was derived.

Results examine the issue of the acceptance of AR technology from a qualitative perspective, which is also a limitation of the research results. The presented results thus form the basis for an in-depth quantitative analysis of the strategic approach to the application of AR.

\section{RESULTS}

\subsection{Augmented Reality Acceptance Model Framework}

After an analysis of the relevant literature on the acceptance and introduction of AR in the industry, specific additional influencing factors could be derived in addition to the TAM 2 model. The following Fig. 1 shows the original TAM 2 model extended by the key results of the literature review, which are shown in italics and dashed text boxes.

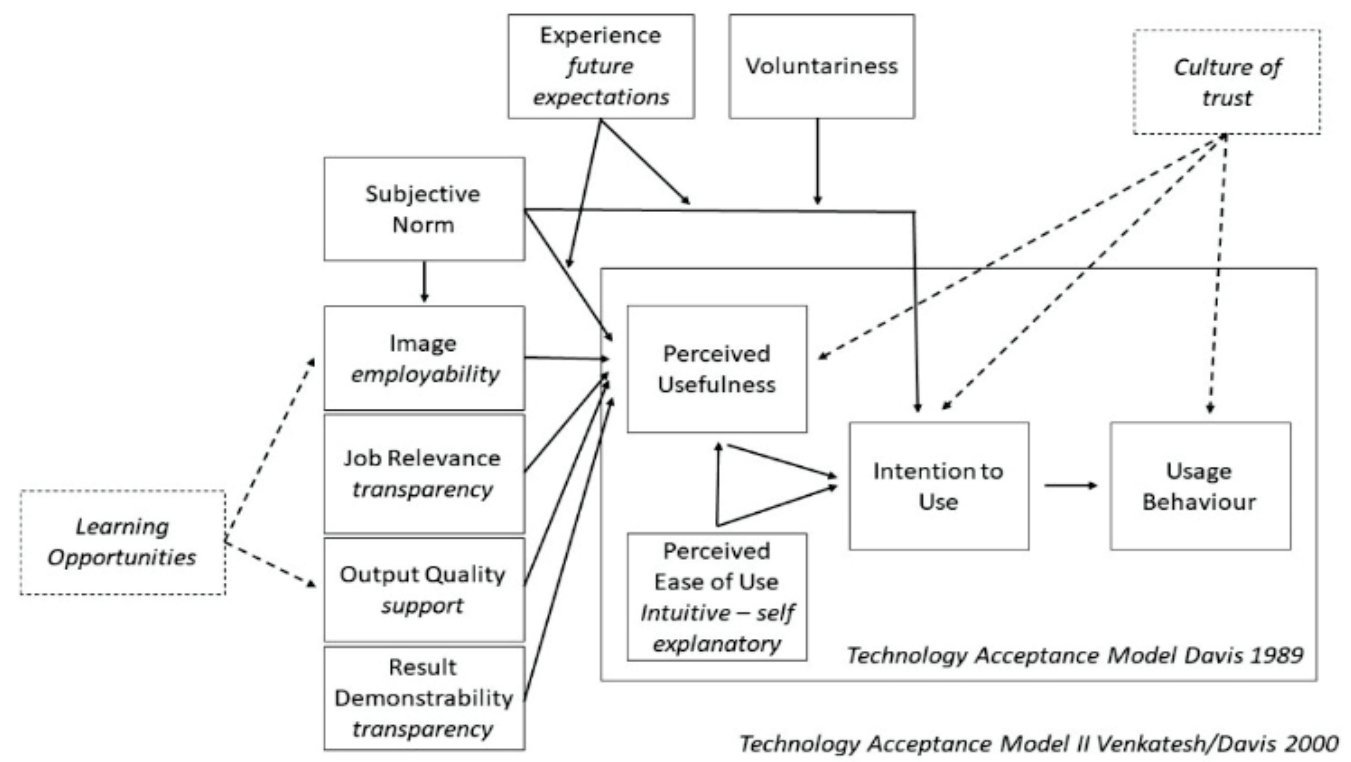

Figure 1 AR Technology Acceptance Model framework

As in TAM 2, there are direct and indirect factors influencing technology acceptance. Comparing the AR specifics, some factors can be assigned to the already existing TAM 2 areas. For example, a transparent handling of the reasons for introducing $\mathrm{AR}$ influences the job relevance, but is also relevant for the result demonstrability. With regard to the usability of the perceived ease of use for AR applications, the terms intuitiveness and self-explanatory can be used to describe the process. Furthermore, the outlined experience must be defined more broadly: positive experiences with AR over time lead to corresponding future expectations. Depending on the level of experience with the technology this can also have an effect from the private sphere. For example, digital natives who have already been involved in 
AR applications also tend to have higher expectations regarding professional AR use.

However, the analysis also revealed the need for two new areas. Due to the broad professional use of AR applications, the technology and the associated devices can be predicted to be of similar importance as the PC. It is a new tool that is revolutionizing daily work along the entire value chain. According to this, a broad mass of people is affected by the change. The demand for suitable, targeted learning and training opportunities is correspondingly high. With reference to TAM 2, the degree of learning possibilities influences in particular the output quality, but also the selfperceived image towards other people perceived as subjectively relevant. However, it should be emphasized that the degree of influence depends to a large extent on the choice of the AR hardware device. If smartphones or tablets are used, the impact on the image in particular is lesser than if data glasses are used. The fear of making oneself ridiculous because of "looking funny" coupled with the fear of making mistakes play a particularly important role.

The second key area is the existence of a culture of trust. Studies show that if employees have the confidence to act on their own responsibility to get support and feedback, the willingness to deal with AR is higher. In this context, a culture of trust describes on the one hand the trust of employees in themselves and the technical solution, and on the other hand, the trust of managers in the decision-making quality of their employees. If the manager in particular does not have this trust, the potential of AR cannot be exploited.

\subsection{Qualitative AR acceptance model}

In addition to the AR specific acceptance criteria, the aim of the present contribution was to ascertain the practical relevance with regard to the introduction and use of AR.

The importance of different perspectives in change processes can be seen from the theory of change management. In addition to the decision-makers, the employees and the organizational framework play a decisive role.

In this respect, the results of the focus group largely confirm the areas of influence identified so far, but highlight additional factors. These are shown as circles in Figure 2. The shading shows the frequency of discussion and the naming of the areas in the focus group. The darker a field, the more often it was considered important. For better understanding, only those areas that were mentioned particularly frequently (nomination rate more than 10\%) were highlighted.

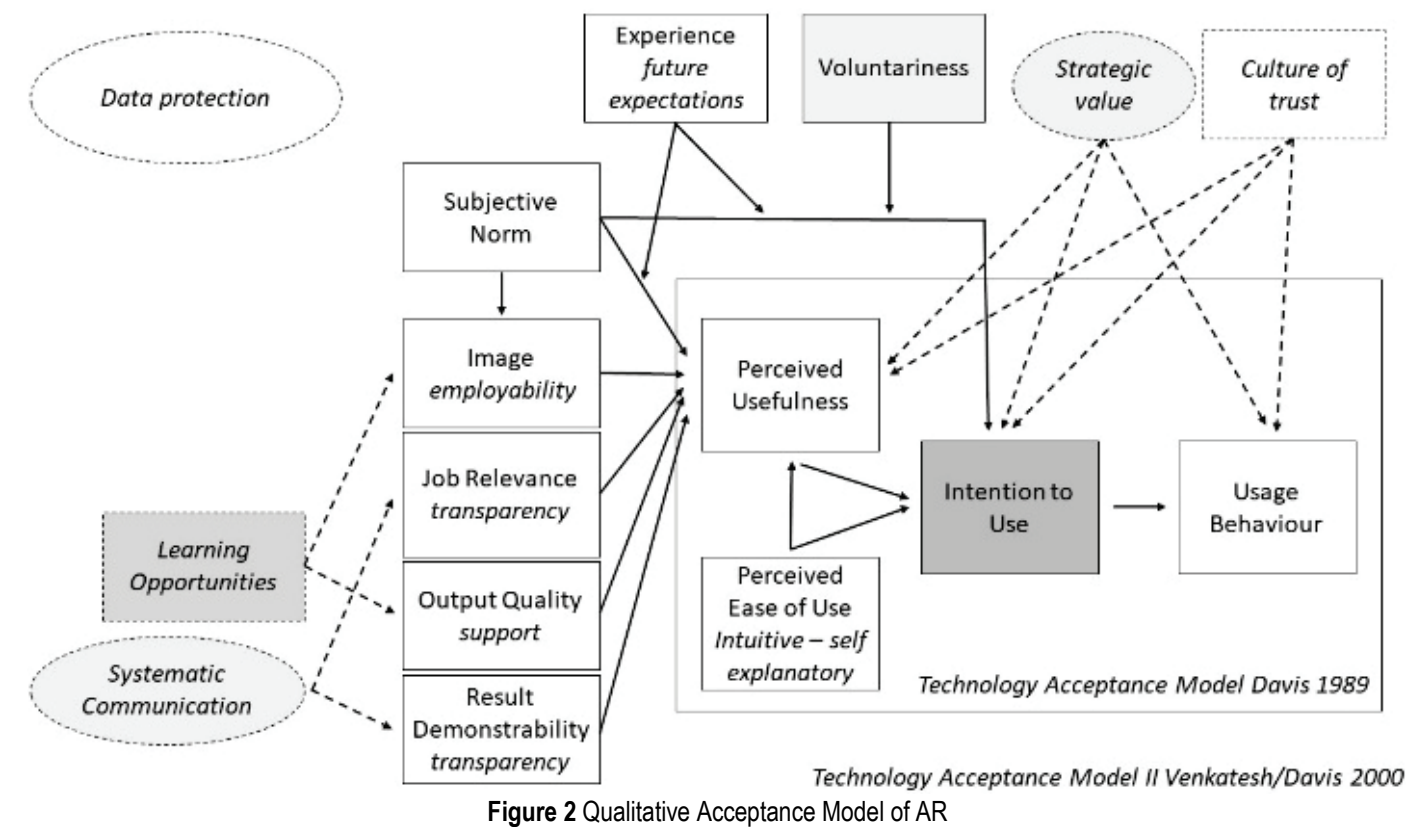

The willingness of employees can be allocated to the intention to use and it was named by the focus group as the most important success criterion for the introduction of AR. Especially from the employees' point of view, but also from a strategic and organizational perspective, willingness generally plays a major role. The focus group thus confirms the existing research in change management, according to which one of the main reasons for the failure of change processes is the resistance of employees.

From the employees' point of view, adequate learning opportunities were named as the second most important success criterion. Especially when dealing with data glasses, it is important that employees are given sufficient time for individual preparation with the device. Only when operating safety is ensured, can AR quickly lead to the desired improvements in the company. It is interesting to note that from the point of view of HR, the need for learning is almost exclusively assigned to employees. However, this contradicts the literature, according to which managers should set an example in change processes and also master the technology with regard to AR.

In addition to adequate learning opportunities, systematic communication was cited by the experts as a key factor for technology acceptance by employees. Therefore, 
this factor was newly added to the outlined model. This again reflects the common literature in change management, according to which systematic communication serves to create an awareness of change, but also to ensure a long-term readiness for change through communication over time. The discussion shows, that in the narrower sense, this factor has a direct effect on the areas of job relevance and result demonstrability in order to maintain awareness.

Another new area is the strategic value of technology. The greater the impact of the technology on the overall company, the more likely it is to be well-perceived by employees and the greater the willingness to use it. According to the focus group, if the strategic benefit is reinforced by an active role model for managers, this also has a direct positive effect on usage behaviour. With regard to $\mathrm{AR}$, the experts noted a high degree of broad use of the technology, since it represents a new working tool for many areas and can change the work processes there in a positive way.

Another interesting result of the study can be assigned to the area of voluntariness in the TAM 2 model. If a company wants to implement AR throughout the company, a high degree of employee participation is of particular importance. In line with the recent change approaches, it is therefore important to give employees at all levels the opportunity to shape the implementation.

The last conspicuous point of discussion concerned data protection. Due to the technical possibilities of AR, especially in the area of video processing and tracking, the experts argued for an explicit consideration of this topic. According to the experts, the consideration of data security is decisive for the user safety of the employees and thus for the acceptance of the new technology. Possible fears of employees of being controlled must be considered and dealt with from the beginning of the introduction process.

Table 1 Overview of the results of the focus group

\begin{tabular}{|l|c|c|c|c|}
\hline $\begin{array}{r}\text { Point of } \\
\text { view }\end{array}$ & Employees & $\begin{array}{r}\text { Decision- } \\
\text { making/strategy }\end{array}$ & $\begin{array}{c}\text { Organisational } \\
\text { framework }\end{array}$ & Total \\
\hline Training/Learning & 7 & 1 & 0 & 8 \\
\hline Communication & 6 & 0 & 0 & 6 \\
\hline Willingness to Use & 14 & 1 & 2 & 17 \\
\hline $\begin{array}{l}\text { Employee } \\
\text { participation }\end{array}$ & 4 & 1 & 2 & 7 \\
\hline Data Protection & 2 & 1 & 0 & 3 \\
\hline Benefit-orientation & 3 & 1 & 1 & 5 \\
\hline Ergonomics & 1 & 0 & 0 & 1 \\
\hline Strategic Value & 1 & 3 & 2 & 6 \\
\hline Total & 39 & 8 & 7 & 54 \\
\hline
\end{tabular}

To summarize, the following Tab. 1 provides a condensed overview of the results of the focus group discussions in total; 54 factors were worked out by the experts from three perspectives: employees, decisionmaking/strategy and organization. The factors were assigned to the presented clusters, which results in the number of mentions shown.

\section{RECOMMENDATIONS}

The contribution was aimed at specifying the generally applicable TAM 2 model explicitly for the technology of Augmented Reality and at incorporating practical experience. This was done in order to show companies the scientifically grounded, and at the same time practiceoriented, recommendations.

First of all, it is important to plan the introduction of AR systematically. An AR strategy should therefore examine and evaluate different areas of application and the necessary technical requirements. It is recommended that the selected AR system be used in a company in as many different ways as possible. Additionally, Klumpp et al. recommend that risk assessment should be carried out to detect possible disruptive factors during implementation and to assess the probability of these factors occurring and their effects.

According to the strategy, it is important to accompany implementation systematically in accordance with change management theories. Regular transparent communication and, in line with Krüger, an intensive participation of employees play a key role. Active communication channels should be established to avoid isolated and unstructured communication.

The article underlines the importance of employees for the implementation process, according to which it is important, especially with such a comprehensive technology as AR, to respond to the needs of employees. Specifically, for AR, these relate to the user-friendliness of the devices and the achievable positive outcome, among other things. To ensure this, learning formats tailored to the individual needs of the employees should be offered. Employees must be able to familiarize themselves with the technology at their own pace and in their comfort zone. It should be noted that, depending on the used AR device, learning can occur on two levels. Not only the use of AR in daily business, but also the operation of the device itself (for example when using data glasses) must be trained.

Finally, it is important to gain the trust of employees on several levels. The involvement and commitment of the works council plays an important role here.

\section{CONCLUSION}

The results of the qualitative analysis of the focus groups confirm the contents of the TAM 2 model on the one hand, but also indicate a need for further research. For example, the model can be used to describe the emergence of technology acceptance in general, but cannot be seen as absolute and conclusive. Depending on the technology and its degree of diffusion in a company, it is necessary to consider further factors in order to achieve a high level of acceptance among employees.

AR can be seen as a far-reaching technology that can be deeply anchored in a company and it does not only affect individual employees. Accordingly, increased attention must be paid to the strategic perspective and overall organizational issues such as data protection. Additionally, AR can not only be used for individual activities, but can also rather be seen 
as a new work tool. It is therefore necessary to develop an accompanying learning concept that covers the individual needs of employees.

Finally, it should be noted that the study is only a qualitative, practical-focused excerpt, which cannot be automatically generalized. Thus, the results largely reflect the experiences of HR managers from different industries. Further research from the perspective of employees or managers would be recommended in any case.

\section{Notice}

The paper will be presented at MOTSP 2020 International Conference Management of Technology - Step to Sustainable Production, which will take place from $30^{\text {th }}$ September $-2^{\text {nd }}$ October 2020 in Bol, island Brač (Croatia). The paper will not be published anywhere else.

\section{REFERENCES}

[1] Frey, C. B. \& Osborne, M. A. (2013). The future of employment: How susceptible are jobs to computerisation? In Oxford Martin Programme on Technology and Employment. Retrieved from https://www.oxfordmartin.ox.ac.uk/ downloads/academic/The_Future_of_Employment.pdf

[2] Spath, D., Ganschar, O., Gerlach, S., Hämmerle, M., Krause, T., \& Schlund, S. (2013). Produktionsarbeit der Zukunft Industrie 4.0. Stuttgart: Fraunhofer Verlag.

[3] Peddie, J. (2017). Augmented Reality - Where We Will All Live. Cham: Springer Nature. https://doi.org/10.1007/978-3-319-54502-8

[4] Gartner Inc. (2018). 5 Trends Emerge in the Gartner Hype Cycle for Emerging Technologies, 2018 - Smarter With Gartner. Retrieved from https://www.gartner.com/ smarterwithgartner/5-trends-emerge-in-gartner-hype-cyclefor-emerging-technologies-2018/

[5] Gartner Inc. (2019). 5 Trends Appear on the Gartner Hype Cycle for Emerging Technologies, 2019 - Smarter with Gartner. Retrieved from https://www.gartner.com/ smarterwithgartner/5-trends-appear-on-the-gartner-hypecycle-for-emerging-technologies-2019/

[6] Sorko, S. R. \& Brunnhofer, M. (2019). Potentials of Augmented Reality in Training. Procedia Manufacturing, 31, 85-90. https://doi.org/10.1016/j.promfg.2019.03.014

[7] Lindner-Lohmann, D., Lohmann, F., \& Schirmer, U. (2016). Personalmanagement ( $3^{\text {rd }}$ ed.). Berlin: Springer Gabler. https://doi.org/10.1007/978-3-662-48403-6

[8] Sutherland, I. E. (1968). A head-mounted three dimensional display. Proceedings of AFIPS 68, 757-764. https://doi.org/10.1145/1476589.1476686

[9] Caudell, T. P. \& Mizell, D. W. (1992). Augmented reality: an application of heads-up display technology to manual manufacturing processes. Proceedings of the Twenty-Fifth Hawaii International Conference on System Sciences, 2, 659669. https://doi.org/10.1109/HICSS.1992.183317

[10] Milgram, P. \& Kishimo, F. (1994). A taxonomy of mixed reality. IEICE Transactions on Information and Systems, 77(12), 1321-1329.

[11] Mann, S., Furness, T., Yuan, Y., Iorio, J., \& Wang, Z. (2018). All Reality: Virtual, Augmented, Mixed (X), Mediated (X,Y), and Multimediated Reality. Retrieved from http://arxiv.org/abs/1804.08386

[12] Speicher, M., Hall, B. D., \& Nebeling, M. (2019). What is mixed reality? Conference on Human Factors in Computing Systems - Proceedings, (April). https://doi.org/10.1145/3290605.3300767

[13] Li, X., Yi, W., Chi, H. L., Wang, X., \& Chan, A. P. C. (2018). A critical review of virtual and augmented reality (VR/AR) applications in construction safety. Automation in Construction, 86 (November), 150-162. https://doi.org/10.1016/j.autcon.2017.11.003

[14] Broll, W. (2013). Augmentierte Realität. In R. Dörner, W. Broll, P. Grimm, \& B. Jung (Eds.), Virtual und Augmented Reality $(V R / A R)$ ( $2^{\text {nd }}$ ed., pp. 315-357). Berlin: Springer Vieweg. https://doi.org/10.1007/978-3-642-28903-3_8

[15] Porter, M. E. \& Heppelmann, J. E. (2019). Why Every Organization Needs an Augmented Reality Strategy. In Harvard Business Review (Ed.), HBR's 10 Must Reads 2019 (pp. 85-108). Retrieved from https://bawar.net/data0/books/ 5cc4319927bb4/pdf/Harvard_Business_Review,_Joan_C_W illiams,_Thomas.pdf

[16] du Toit, G., Dullweber, A., Hatherall, R., \& Moreau, M. (2018). Customer Experience Tools and Trends 2018. Retrieved from Bain \& Company website: https://www.bain.com/insights/customer-experience-toolsand-trends-2018/

[17] Dalton, J. (2019). Virtual reality and augmented reality: Trust in a new way of working. Retrieved from https://www.pwc.at/ de/veranstaltung/all-eyes-on-trust-2019/all-eyes-on-trustdalton.pdf

[18] IDG Business Media GmbH (2019). Studie Augmented \& Virtual Reality. Retrieved from https://www.ptc.com//media/Files/PDFs/Augmented-Reality/19-08-ARVR-Studie2019-V4.pdf

[19] Ciortea, A., Mayer, S., \& Michahelles, F. (2018). Repurposing manufacturing lines on the fly with multi-agent systems for the web of things. Proceedings of the International Joint Conference on Autonomous Agents and Multiagent Systems, AAMAS, 2(i), 813-822.

[20] Masood, T. \& Egger, J. (2019). Augmented reality in support of Industry 4.0-Implementation challenges and success factors. Robotics and Computer-Integrated Manufacturing, 58(August), 181-195. https://doi.org/10.1016/j.rcim.2019.02.003

[21] Klumpp, M., Hagemann, V., Ruiner, C., Neukirchen, T. J., \& Hesenius, M. (2019). Arbeitswelten der Logistik im Wandel Gestaltung digitalisierter Arbeit im Kontext des Internet der Dinge und von Industrie 4.0. In B. Hermeier, T. Heupel, \& S. Fichtner-Rosada (Eds.), Arbeitswelten der Zukunft. Wie die Digitalisierung unsere Arbeitsplätze und Arbeitsweisen verändert (pp. 67-85). Wiesbaden: Springer Fachmedien. https://doi.org/10.1007/978-3-658-23397-6_5

[22] Grant, A. M. \& Parker, S. K. (2009). Redesigning Work Design Theories: The Rise of Relational and Proactive Perspectives. The Academy of Management Annals, 3(1), 317-375. https://doi.org/10.1080/19416520903047327

[23] World Economic Forum. (2016). The Future of Jobs: Employment, Skills and Workforce Strategy for the Fourth Industrial Revolution. Retrieved from http://www3.weforum.org/docs/WEF_Future_of_Jobs.pdf

[24] Bauernhansl, T. (2014). Die Vierte Industrielle Revolution Der Weg in ein wertschaffendes Produktionsparadigma. In T. Bauernhansl, M. Ten Hompel, \& B. Vogel-Heuser (Eds.), Industrie 4.0 in Produktion, Automatisierung und Logistik: Anwendung, Technologien und Migration (pp. 5-35). Wiesbaden: Springer Fachmedien. https://doi.org/10.1007/978-3-658-04682-8_1

[25] Ertl, C., Herzfeldt, A., Kapadia, A., Floerecke, S., \& Krcmar, H. (2019). Entwicklung eines Vorgehensmodells zur 
Einführung mobiler IT-Lösungen bei Instandhaltungsprozessen. HMD Praxis Der Wirtschaftsinformatik, 56, 647659. https://doi.org/10.1365/s40702-019-00496-8

[26] Wiesinger, F. \& Thiessen, T. (2016). Mittelstand im digitalem Wandel: Bedarfs- und Trendanalyse zu Führungskultur und Veränderungsmanagement. Retrieved from https://kommunikation-mittelstand.digital/content/uploads/ 2017/06/Studie-Bedarfs-und-TrendanalyseVeraenderungsmanagement.pdf

[27] Widmann, A., Gerlach, P., \& Stuska, T. (2017). An Astronaut is Guide to Change. Retrieved from https://www.moonroc.de/ fileadmin/user_upload/content/research/MOONROC_An_Ast ronauts_Guide_To_Change.pdf

[28] Krüger, W. (2006). Excellence in Change: Wege zur strategischen Erneuerung ( $3^{\text {rd }}$ ed.). Wiesbaden: Gabler.

[29] Rüttgers, C. \& Hochgürtel, K. (2019). Digitalisierung der Arbeit und des HR-Managements - Eine empirische Analyse der Einstellungen von Beschäftigten. In B. Hermeier, T. Heupel, \& S. Fichtner-Rosada (Eds.), Arbeitswelten der Zukunft. Wie die Digitalisierung unsere Arbeitsplätze und Arbeitsweisen verändert (pp. 223-247). Wiesbaden: Springer Gabler. https://doi.org/10.1007/978-3-658-23397-6_13

[30] Coovert, M. D. \& Thompson, L. F. (2013). The psychology of workplace technology. New York: Routledge. https://doi.org/10.4324/9780203735565

[31] Welpe, I. M., Brosi, P., \& Schwarzmüller, T. (2018). Digital Work Design: Die Big Five für Arbeit, Führung und Organisation im digitalen Zeitalter. Frankfurt: Campus.

[32] Kluge, A. \& Hagemann, V. (2016). Neue und Soziale Medien in der Fertigung und der Personalentwicklung - am Beispiel von Industrie 4.0 und E-coaching aus Sicht der AOPsychologie. Wirtschaftspsychologie, 18(1), 5-21.

[33] Wilkens, U. \& Ruiner, C. (2014). Konfigurationen von new employment relationships - Zur (In-)Stabilität von Arbeitsbeziehungen mit hochqualifizierten Arbeitskräften. In J. Sydow, D. Sadowski, \& P. Conrad (Eds.), Managementforschung 24: Arbeit - eine Neubestimung (pp. 63-100). Wiesbaden: Springer. https://doi.org/10.1007/978-3-658-06274-3_3

[34] Dick, M., Degenhardt, B., Schulze, H., \& Wehner, T. (2015). Der Novartis-Campus: Eine Fallstudie zu Produktivität, Wohlbefinden und Authentizität im Multispace Office. Wirtschaftspsychologie, 17(1), 105-116.

[35] Di Vaio, A., Palladino, R., Hassan, R., \& Alvino, F. (2020). Human resources disclosure in the EU Directive 2014/95/EU perspective: A systematic literature review. Journal of Cleaner Production, 257. https://doi.org/10.1016/j.jclepro.2020.120509

[36] Venkatesh, V. \& Davis, F. D. (2000). Theoretical extension of the Technology Acceptance Model: Four longitudinal field studies. Management Science, 46(2), 186-204. https://doi.org/10.1287/mnsc.46.2.186.11926

[37] Davis, F. D., Bagozzi, R. P., \& Warshaw, P. R. (1992). Extrinsic and Intrinsic Motivation to Use Computers in the Workplace. Journal of Applied Social Psychology, 22, 11111132. https://doi.org/10.1111/j.1559-1816.1992.tb00945.x

[38] Moore, G. C. \& Benbasat, I. (1991). Development of an instrument to measure the perceptions of adopting an information technology innovation. Information Systems Research, 2, 192-222. https://doi.org/10.1287/isre.2.3.192

[39] Fishbein, M. \& Ajzen, I. (1975). Belief, attitude, intention, and behavior: An introduction to theory and research. Reading: Addison-Wesley.

[40] Hartwick, J. \& Barki, H. (1994). Explaining the role of user participation in information system use. Management Science, 40, 440-465. https://doi.org/10.1287/mnsc.40.4.440
Authors' contacts:

Sabrina Romina Sorko, MMag. Dr.

Industrial Management,

FH JOANNEUM University of Applied Sciences,

Werk-VI-Straße 46, 8605 Kapfenberg, Austria

+433165453-8309,

SabrinaRomina.Sorko@fh-joanneum.at

Joachim Komar, BSC.

Industrial Management,

FH JOANNEUM University of Applied Sciences,

Werk-VI-Straße 46, 8605 Kapfenberg, Austria

+433165453-8342,

Joachim.Komar2@fh-joanneum.at 